\title{
A VIOLÊNCIA EM S. BERNARDO: A RELAÇÃO ENTRE PAULO HONÓRIO E MADALENA
}

\author{
Clarissa Loyola Comin ${ }^{1}$ \\ Luís Gonçales Bueno de Camargo ${ }^{2}$
}

Resumo: Este artigo pretende demonstrar como se conforma a relação de violência em S. Bernardo a partir da relação estabelecida entre o narrador-personagem, Paulo Honório, e sua esposa, Madalena. Primeiro, apresentamos a ideia de internalização de traços sociais pela forma literária - presente de maneira mais canônica em Candido e Schwarz - e entrevista sob a ótica da violência, mais recentemente, em Crítica em tempos de violência, de Jaime Ginzburg. Na sequência, explicitamos nosso aporte teórico para pensar a violência a partir do ensaio "Para uma crítica da violência" de Walter Benjamin. Por fim, analisamos trechos do romance que evidenciam a hipótese apresentada.

Palavras-chaves: violência; romance de 30; Graciliano Ramos; S. Bernardo

\begin{abstract}
This paper aims to indicate the conformation of violence in the novel S. Bernardo, seeing how it's configured in the relation between the narrator, Paulo Honório, and his wife Madalena. First, we present the idea of internalization of social traces by the literary form, as formulated canonically by Antonio Candido and Roberto Schwarz, and developed more recently in its relation to violence by Jaime Ginzburg in his book Crítica em tempos de violência. Following that, we define our theoretical approach to violence, whose backbone is Walter Benjamins essay "Para uma crítica da violência". Finally, in trying to verify our hypothesis, we analyse passages of the romance.
\end{abstract}

Keywords: violence; 30's novel; Graciliano Ramos; S. Bernardo

Mestranda em Estudos Literários na UFPR. Bolsista CNPq. E-mail: cominclarissa@gmail.com

2 Professor do Programa de Pós-Graduação em Letras da UFPR. E-mail: Luis@ufpr.br 


\section{INTERNALIZAÇÃO DO SOCIAL PELO LITERÁRIO}

No cenário brasileiro, a ideia de internalização do social pelo literário foi cuidadosamente explanada por Antonio Candido, em "Crítica e Sociologia”. Segundo o crítico, a fusão entre texto e contexto se dá na medida em que aquilo que é externo - o entorno social - não é relevante apenas casuísticamente, mas também como elemento constitutivo da trama, tornando-se, consequentemente, interno - componente da organicidade do romance. Portanto, a consideração dos fatores sociológicos só é rentável uma vez que: 1) seja elegida pelo crítico como foco do seu trabalho em detrimento das demais possibilidades críticas: estruturalista, psicanalítica, pós-estruturalista, etc; 2) Alimente a economia da obra em análise, servindo como mola propulsora para o desenrolar da trama e estabelecimento de conflitos. Por outro lado, Roberto $S c h w a r z^{3}$ parte do princípio que os bons romances seriam aqueles em que os autores conseguem dramatizar com êxito as estruturas sociais circundantes, excluindo a presença destes traços nas obras "mal realizadas". O interesse que o crítico atribui à "aclimatação" do romance advém justamente de uma fratura entre a forma, que seguia os moldes da versão europeia, e a realidade brasileira descrita. O romance teve de passar por um árduo processo de remanejamento formal para que desse conta de internalizar a dinâmica social ao seu redor, resultando em um sensível descompasso estético que reflete no limite o social, discussão presente no reconhecido "As ideias fora do lugar".

Ou seja, fica clara a distinção do entendimento de cada crítico sobre a internalização. Diferente de Schwarz, Candido crê que o romance sempre traz, em alguma medida, a manifestação estética das estruturas sociais, e o papel do crítico literário seria o de pesar a relevância deste traço para sua análise $e^{4}$. Na esteira do pensamento destes dois críticos, acrescentamos para a discussão as ideias apresentadas por Jaime Ginzburg em Crítica em Tempos de Violência, onde temos a coadunação entre experiências de violência e seu reflexo na literatura brasileira. Ginzburg (2012, p. 13): "estima contribuir com a narrativa de uma história da literatura brasileira sob a perspectiva da violência", por acreditar que a violência sempre esteve presente no processo constitutivo de nossa nação, pensando nos genocídios, massacres, chacinas e políticas repressoras. Este trecho parece esclarecer a empreitada de Ginzburg:

Compreendendo a literatura como produção constituída historicamente, e não como objeto fechado em si mesmo, podemos formular a hipótese de que a enorme carga de violência que caracterizou a história brasileira tenha implicações nas obras literárias.(2012, p. 134)

Importante para este trabalho é observar como o crítico parece dialogar com aquilo que Schwarz defende com a ideia de internalização, quando expõe a presença de "antagonismos formais" (expressão adorniana). ${ }^{5}$ Ou seja, para Ginzburg a:

\footnotetext{
3 Cf.: SCHWARZ, Roberto. "Acumulação literária e nação periférica" in Um mestre na periferia do capitalismo. São Paulo: Duas Cidades/Ed. 34, 2000.

${ }^{4}$ Cf.: CANDIDO, Antonio. "Crítica e Sociologia”, in Literatura e Sociedade. Rio de Janeiro: Ouro sobre Azul, 2010.

${ }_{5}$ Deixo claro, no entanto, que a aproximação se faz por minha conta e risco, uma vez que Ginzburg defende a perpe-
} 
incorporação à forma artística de um impasse, de uma negatividade constitutiva, em que a forma de uma obra, em termos estilísticos e historiográficos, entra em confronto com as tendências hegemônicas de produção cultural, bem como com os valores ideológicos dominantes.(2012, p. 135)

É mais especificamente no ensaio "A Violência na Literatura Brasileira: Notas sobre Machado de Assis, Graciliano Ramos e Guimarães Rosa” que temos a aplicação direta desta proposta, a partir do estudo dos três autores: Machado de Assis e seu conto "A Causa Secreta”, Graciliano Ramos e uma cena de S. Bernardo e Guimarães Rosa, na figura paradoxal do narrador-personagem Riobaldo em Grande Sertão: Veredas. Ginzburg observa uma maturação no modo como estes escritores formulam a violência, percebida a partir das diferentes posições dos narradores diante dos episódios violentos dramatizados em cada texto.

Assim, deixando claro o que entendemos por internalização do social pelo estético-literário e comprovando a rentabilidade de pensarmos a violência como um desses aspectos, prosseguimos com os desdobramentos deste raciocínio, esclarecendo nosso entendimento e uso da violência neste trabalho.

\section{ESCLARECENDO O CONCEITO DE VIOLÊNCIA}

Segundo Walter Benjamin, em seu ensaio "Para uma crítica da violência” (2011), a violência é elemento constitutivo das sociedades, uma vez que é encarada como necessária para instituir e manter a ideia de direito e, consequentemente, de justiça. Assim, o âmbito das relações éticas passa a ser balizado por duas premissas básicas: direito e justiça. Ou seja: a violência deve ser observada na medida em que intervém na dinâmica destas relações. ${ }^{6}$ O Estado, arrogando para si o exercício pleno do direito, circunscreve também para si o monopólio da violência. Ao exemplificar suas possíveis manifestações, Benjamin dá como exemplo a greve, pois ela é capaz de modificar as relações de poder na medida em que intervém nas relações éticas entre empregador e empregado.

No ensaio, são confrontadas duas perspectivas: a do direito natural e do direito positivo. Ora, o direito natural opera com a premissa de que para a obtenção de fins naturais, que são, por definição, justos, é válido o exercício de meios violentos. Vemos que o narrador de $S$. Bernardo pauta suas ações nesta assertiva durante boa parte do romance. Ele dribla os possíveis julgamentos morais de seus leitores, que podem suspeitar de seus meios, ao acenar para o fim justo; a construção de uma propriedade moderna e próspera. Ainda com Benjamin, em seu ensaio ele sublinha que, em um primeiro momento, a violência em ato se faz necessária afim de que o direito se instaure e constitua o poder junto a uma determinada sociedade. Uma vez que o processo obtenha êxito, não é mais necessário o exercício

tração desta violência enquanto trauma que o romance dá conta de elaborar, e Schwarz não está falando, em momento algum, de violência no romance brasileiro.

${ }^{6}$ Este ensaio é utilizado apenas em aspectos que julgamos procedentes à análise do romance. Há várias questões nele trabalhadas que não estão especificadas e esclarecidas aqui. Vale ressaltar a amplitude prevista neste ensaio para o conceito de violência, que não se restringe apenas aos atos, mas a qualquer ação que intervenha nas relações éticas. 
extensivo da violência. Ora, o que temos na narrativa em questão é o descompasso entre a instauração deste poder a partir da violência e sua manutenção. Esta é a perspectiva se mostra ameaçadora, uma vez que a posição social de Paulo Honório não se encontra bem alicerçada. Ou seja, a instauração do poder acaba sendo sempre reencenada, pois sua manua tenção está constantemente ameaçada.

No entanto, o narrador não se dá conta da contrapartida de seus excessos, que desencadeiam aquilo que Benjamin chama em seu ensaio de violência divina. Esta seria a ruptura definitiva da própria violência, uma vez que não prevê a instauração de um novo direito. No romance, esta modalidade pode ser observada no suicídio de Madalena. Com seu gesto, ela silencia qualquer continuidade da violência exercida contra sua pessoa. Em nossa análise, a escolha da relação do casal tem um sentido estratégico, já que a violência, neste caso, não é exercida por Paulo Honório, mas pela própria Madalena. Além disso, o ato da personagem desestrutura as bases de sua relação com o mundo; aliado às mudanças propostas pela revolução, o exercício do poder pelo narrador é impossibilitado.

Apresentado e demonstrado o conceito de violência com breves exemplos do romance, partimos agora para a análise mais pontual, cerrada na relação entre o protagonista e sua esposa.

\section{PRIMEIRAS VIOLÊNCIAS NÃO PASSARAM DESAPERCEBIDAS}

Apesar dos conflitos entre Madalena e Paulo Honório jamais descambarem para a violência física, é patente seu desejo obsessivo de dominação sobre Madalena. Tal sujeição faz-se necessária porque é assim que o narrador significa para si o êxito de suas investidas e, uma vez que o casamento é encarado como uma empreitada, assim como o fora a conquista das terras de São Bernardo e o assassinato de Mendonça, é preciso que a esposa seja submetida para que o ciclo se complete.

A conquista de Madalena se dá segundo o modelo de outras já narradas anteriormente, como tomar a propriedade de Padilha e o assassinato de Mendonça. No capítulo XV, que poderia se chamar "A Negociação”, o narrador fecha o cerco sobre D. Glória e a sobrinha, encurralando-as até que a resposta quanto ao casamento seja positiva. Paulo Honório quer estabelecer a data para que se consume o matrimônio, mas Madalena demonstra cautela, e arroga o prazo de um ano, ao que Paulo Honório redargui, impositivo: “- Um ano? Negócio com prazo de um ano não presta. Que é que falta? Um vestido branco faz-se em vinte e quatro horas [grifo nosso]."(p. 106) Assim, ele consegue o que quer e deixa clara sua postura de proprietário obstinado, homem de negócios que opera junto à lógica capitalista.

Após o casamento as diferenças entre o casal começam a insurgir. Madalena vem de uma experiência de vida livre. Curiosa, quer entender o funcionamento da propriedade, conhecer os trabalhadores, ou seja, entrar em contato com tudo aquilo que Paulo Honório, dentro de sua lógica patriarcalista e arcaica, julgava absurdo a uma mulher desejar. Buscando alguma conciliação, autoriza a esposa a exercer um ofício, mas próprio a sua condição feminina: “- Esses caboclos são uns brutos. Quer trabalhar? Combino. Trabalhe com Maria das Dores. A gente da lavoura só comigo.” Ao que Madalena responde: “- A ocupação de 
Maria das Dores não me agrada. E eu não vim aqui para dormir.” (p. 110). Ora, o serviço de Maria das Dores restringe-se aos afazeres domésticos e Madalena, mulher letrada, não teria muito com o que contribuir nesse sentido. Ela pretende agir de acordo com sua competência intelectual, surgindo aqui sua faceta engajada, que desde o início reivindica seu espaço.

Vemos outra prova desse descompasso no capítulo XXI. Aqui, por conta das sugestões de Madalena, Paulo Honório encomenda material para a escola, mas ao receber a fatura descobre uma inesperada despesa de seis mil reis. Afrontado com o desperdício, ele busca alguém - que não seja Madalena, óbvio - em que possa descontar sua raiva. A vítima é Marciano, espancado na frente de Padilha, sob alegação de que deixava o gado morrer de fome no curral. Enquanto isso, Madalena acompanhava tudo à distância e ao se aproximar do marido explode indignada com a cena. Paulo Honório não consegue entender a revolta da esposa. Ela o indaga: “- Mas é uma crueldade. Para que fez aquilo?” (p. 129). O narrador, como sempre, quer justificar arrazoadamente suas atitudes violentas, e conclui afirmando que, por vontade de Deus, Marciano sequer era um homem, mas sim um molambo. Madalena ainda ensaia uma réplica, mas o diálogo terminam com uma fala final de Paulo Honório que, apelando para o poder que lhe é de direito, diz: “- Fiz aquilo porque achei que devia fazer aquilo. E não estou habituado a justificar-me, está ouvindo?” (p. 129).

Lembremos que o intuito inicial de Paulo Honório ao empreender o matrimônio era "[...] preparar um herdeiro para as terras de São Bernardo." (p. 67). No entanto, Madalena engravida e tem o filho, e a menção a tais episódios é breve e desinteressada, donde concluímos que o interesse da relação agora era dominar Madalena e trazê-la para junto de si, como maneira de comprovar sua lógica acerca do funcionamento do mundo. Como usar a violência física contra a esposa está fora de questão, Paulo Honório desespera-se e não encontra outra saída a não ser o ciúme doentio que passa a nutrir por ela e seus amantes fantasmagóricos. Começando de maneira sutil, este ciúme passa a ganhar contorno e relevo no desenrolar do romance.

É na festa de dois anos de casamento onde vemos essa manifestação ainda incipiente: uma cena em que Paulo Honório se incomoda ao ver Padilha colhendo rosas no jardim. O subordinado diz que o faz a pedido de Madalena, ao que Paulo Honório responde: "A d. Madalena não dá ordens." (p. 147). Novamente uma reafirmação do constante medo do narrador de perder o controle sob sua suposta propriedade. Embora não detenha poder financeiro, Madalena ocupa um lugar que, pelo menos aos olhos dos subordinados, parece permitir o exercício da dominação. Diante dos “inferiores", Paulo Honório imprime uma distância a partir da violência. À esposa é permitida uma relativa proximidade, que a imbui de certo prestígio entre os subordinados. Expô-la à violência seria confiná-la na distância, e permitir a aproximação significaria diluir a autoridade. Madalena utiliza o espaço de manobra que seu status de esposa de proprietário proporciona para praticar ações humanitárias e atenuar as mazelas em que seu marido encerra seus trabalhadores. Acreditamos que a partir daqui Paulo Honório passa a perceber a esposa como alguém definitivamente impassível à assimilação.

Durante a festa, o interesse de Madalena por questões políticas e sociais o incomodam, e este desconforto acaba chegando ao místico (teria ela alguma religião?). Paulo Honório admite a precariedade da sua religiosidade, por crer "que, em parte, ela é dispensável num 
homem. Mas mulher sem religião é horrível.” (p. 155). Ou seja, o autoritarismo é mais uma vez utilizado como chancela para exercício da violência, uma vez que o narrador resguarda seu direito de não professar nenhuma fé, mas se incomoda com a possibilidade de que Madalena não a tenha. Chegando ao paroxismo, ele conclui: "Mulher sem religião é capaz de tudo." (p. 155). Se pensarmos nas últimas palavras que encerram o capítulo ("e comecei a sentir ciúmes") vemos que o excerto anterior faz todo o sentido e já funciona como uma justificação para o ciúme doentio que se agrava na sequência.

\section{CONSTRUÇÃO DO CIÚME}

Observemos que os ciúmes de Paulo Honório se colocam apenas após os dois primeiros anos de casamento. É como se no período anterior ele estivesse obstinado a trazer a esposa para seu universo, valendo-se de uma categoria diferente das usuais (anulação, aniquilação, submissão), discutidas por Luís Bueno (2006) em sua tese, em proveito de uma nova modalidade: a assimilação ${ }^{7}$. Paulo Honório foi arrebatado pela ingenuidade típica dos apaixonados: a crença de que somos capazes de colar a imagem real do ser amado naquela que repousa em nosso ideal. Aqui há uma empreitada em que, a despeito das semelhanças que guarda para com as que o narrador já exercera, está em jogo um investimento afetivo que pela primeira vez é desembolsado por Paulo Honório. Ora, se mapearmos os acontecimentos da vida do casal durante estes dois primeiros anos, sabemos que as tentativas de conciliação, de aceitação, de relevação das contrariedades são constantes. Quando o ciúme se instaura, Paulo Honório abandona-se vertiginosamente ao delírio, por não ver outra saída que não o ciúme para canalizar sua frustração junto ao fracasso no processo de dominação da esposa.

Ciente disso, Paulo Honório começa a praticar violências implícitas contra aqueles que aceitam Madalena. O primeiro bode expiatório é Padilha: passa quatro meses sem pagar-lhe o ordenado e priva-lhe do outrora convívio cotidiano em sua casa. A violência que não se pode concretizar em ato passa a configura-se em ciúme. Com isso, Paulo Honório começa a criar uma imagem distorcida de sua esposa, colecionando juízos nocivos e ameaçadores: "Madalena, propriamente, não era uma intelectual. Mas descuidava-se da religião, lia os telegramas estrangeiros.” (p. 159) Ora, a desconfiança sobre a esposa se constrói a partir de alguns dados centrais: a aparente ausência de religiosidade, o interesse por assuntos políticos e sociais e o descaso para com o filho. Neste trecho, a ligação lhe parece óbvia: "Eu tinha razão para confiar em semelhante mulher? Mulher intelectual.” (p. 160). Levando suas suspeitas ao limite, Paulo Honório chega até mesmo a desconfiar se é realmente pai de seu filho, aproximando-se do personagem Bento Santiago, em Dom Casmurro.

O único momento em que Paulo Honório formula uma violência física contra Madalena é neste trecho: "O meu desejo era pegar Madalena e dar-lhe pancada até no céu da boca." (p. 163). Mas isto fica restrito ao campo da possibilidade. Jamais se atreve a pôr em prática e muito menos a comentar com alguém suas ideias e desconfianças sobre a esposa. É como

\footnotetext{
7 Cf. BUENO, Luís. Uma história do romance de 30. São Paulo: EDUSP, 2006.
} 
se a agressão só estivesse chancelada caso obtivesse uma prova concreta de suas suspeitas. Enquanto isso, Paulo Honório agride a esposa como pode. Mas o comportamento contraditório está posto em vários momentos como, por exemplo, durante a discussão iniciada devido a uma carta que Madalena escrevia para Azevedo Gondim, descambando numa desnecessária e exagerada agressão verbal. Pela primeira vez Madalena se coloca em pé de igualdade com Paulo Honório, negando-se a mostrar a carta a ele, diz furiosa: "— Vá para o inferno, trate da sua vida." ao que o narrador replica: "- Deixa ver a carta, galinha." (p. 165). Na sequência, trocam diversos insultos, culminando naquele que mais lhe incomoda: assassino.

Logo depois, Paulo Honório aparece apaziguado, chegando a relativizar o surto demonstrado momentos antes: "Madalena era honesta, claro. Não mostrara o papel para não dar o braço a torcer, por dignidade, claríssimo. Ciúme idiota." (p. 169). O que leva o marido a sustentar tal hipótese é demonstração de um nítido mecanismo compensatório para sua incapacidade de subjugá-la, de trazê-la para sua velha ordem. Madalena nasceu e cresceu na cidade, inserida desde cedo em uma nova ordem, em que 'teoricamente' as instâncias de poder já estariam assentadas e atuantes. Assim, Paulo Honório, que em alguma medida parece ter consciência disto, vai despejar seu descontentamento reprimido sobre Padilha: "Depois da violência da manhã, sentia-me cheio de otimismo, e a brutalidade que há em mim virava-se para o mestre-escola." (p. 170).

Paulo Honório cria para si uma lógica de distorções. Por não admitir a personalidade da esposa, diametralmente oposta a sua, passa a agenciar uma série de fatores que, costurados pelo delírio, conformam-se enquanto indícios reais de que a esposa o traía. A certa altura, o narrador elucubra:

Se eu tivesse uma prova de que Madalena era inocente, dar-lhe-ia uma vida como ela nem imaginava. Comprar-lhe-ia vestidos que nunca mais se acabariam, chapéus caros, dúzias de meias de seda. Seria atencioso, muito atencioso, e chamaria os melhores médicos da capital para curar-lhe a palidez e a magrém. Consentiria que ela oferecesse roupa às mulheres dos trabalhadores. (p. 176)

Ou seja, anseia obter uma prova de que a suspeita inventada por ele mesmo seja falsa, para, a partir daí, conceder à esposa um tratamento digno do lugar que ocupa. É como se Paulo Honório estivesse calcificado demais na sua postura, incapaz de demover-se, nem mesmo pela rendição que o amor parece lhe oferecer.

\section{VIOLÊNCIA COMO ÍMPETO DESTRUIDOR}

Com o agravamento de sua paranoia, o narrador vai progressivamente se encerrando em um universo inescrutável. Para ele, D. Glória seria alcoviteira da sobrinha. Passa a suspeitar dos caboclos da lavora, de que D. Margarida estivesse levando e trazendo cartas dos amantes e até mesmo de padre Silvestre, que, a despeito do ofício clerical, passava a significar uma ameaça. Num lapso de consciência, Paulo Honório confessava: "Creio que 
estava quase maluco." (p. 178). Em uma de suas muitas noites insones, Paulo Honório suspeita ter ouvido passos do lado de fora, e resolve disparar seu rifle. Madalena acorda sobressaltada, e ele irredutível lhe diz: "São seus parceiros que andam rondando a casa." (p. 179). Sem obter resposta, indaga, desesperado: “- É assobio ou não é? Marcou entrevista aqui no quarto, em cima de mim? É só o que falta.”(p. 180). Madalena sequer ensaia dizer algo. Sua reação é chorar.

A partir deste ponto, sentimos que o desenlace se aproxima. Paulo Honório já chegou ao ápice de sua loucura e Madalena ao de sua depressão. O narrador passa a relembrar as inúmeras conversas inúteis que tivera com a esposa. Parece que já está ensaiando um discurso que, em breve, talvez sirva para inocentá-lo ou pelo menos aliviar a possível culpa que o leitor venha a apontar. Imputa a falta de entendimento a diferenças na linguagem, que acarretam claramente uma diferença na visão de mundo:

O que eu dizia era simples, direto, e procurava debalde em minha mulher concisão e clareza. Usar aquele vocabulário, vasto, cheio de ciladas, não me seria possível. E se ela tentava empregar a minha linguagem resumida, matuta, as expressões mais inofensivas e concretas eram para mim semelhantes às cobras: faziam voltas, picavam e tinham significação venenosa. (p. 182).

No capítulo XXXI, o desfecho trágico. Paulo Honório acredita ter finalmente a 'prova' que precisava para acusar Madalena de traição, ao encontrar, no pomar, uma "folha de prosa" que fora visivelmente escrita por ela. Neste momento assegura-se de que "[a]quilo era trecho de carta, e de carta a homem. Não estava lá o nome do destinatário, faltava o princípio, mas era carta a homem, sem dúvida."(p. 185) Transtornado, sai em direção à igreja, e encontra Madalena no caminho. Segurando-a pelo braço, entram e começam a discutir. Paulo Honório se irrita diante da tranquilidade da mulher, e pensa: "Ferviam dentro de mim violências desmedidas. As minhas mãos tremiam, agitavam-se em direção a Madalena. Apertei-as para conter os movimentos [...].” (p. 187).

Ao pedir que a mulher leia a carta, ela o faz sem demonstrar espanto. Quando o marido indaga quem seria o destinatário, ela responde: “- Você verá. Está em cima da banca. Não é caso para barulho. Você verá." (p. 189). Com isso, desvanece toda sua fúria e daí instaura-se uma atmosfera de introspecção, propícia para a confissão. Pela primeira vez Madalena verbaliza aquilo que a incomodava e julgava ser o motivo principal dos desentendimentos do casal: “- O que estragou tudo foi esse ciúme, Paulo." (p. 188). O narrador sente ímpetos de desculpar-se, mas o orgulho reprime-lhe o gesto. Assumindo sua impotência, pensa: "Muitas vezes por falta de um grito se perde uma boiada." (p. 188).

Durante o silêncio em que permanece, o narrador afirma para si mesmo que "matá-la era ação justa. Para que deixar viva mulher tão cheia de culpa? Quando ela morresse, eu lhe perdoaria os defeitos." (p. 188). Mais uma vez a tentativa de convencer o leitor de que o uso de meios violentos é necessário. Neste caso para um fim igualmente violento: o assassinato da mulher. É uma lógica difícil de acompanhar, mas é a partir dela que podemos reiterar, novamente, a hipótese de que a violência estrutura a narrativa: a eliminação do objeto de posse resultaria em uma dominação completa. Mas é Madalena quem toma as rédeas da 
ação e, paradoxalmente, age como sujeito e objeto. Seu suicídio desestabiliza as relações de poder dentro da propriedade, e causa um profundo abalo no narrador.

Nos capítulos que se seguem ao suicídio de Madalena, temos um Paulo Honório abatido e transtornado. Apesar de tentar retomar o curso cotidiano de sua vida, acaba se dando conta de uma mudança fundamental em sua maneira de ver o mundo: "[...] o entusiasmo esfriou depressa. Aquilo era meio de vida, não era meio de morte." (p. 197). Pouco a pouco, todos aqueles que vivenciaram "os tempos de Madalena” dão um jeito de se afastar. Primeiro, D. Glória e, depois, seu Ribeiro: “- Esta casa me provoca recordações muito pungentes.”(p. 201). Por fim, Padilha e padre Silvestre também abandonam a propriedade, juntando-se às tropas revolucionárias quando estoura a revolução.

Sabemos que a morte de Madalena coincide com a revolução de 1930, apresentada de forma secundária nos capítulos finais. O partido político de Paulo Honório vai abaixo, perdendo as regalias e a supremacia de outrora, no entanto isso não parece incomodá-lo como deveria. Coincidência ou não, os ideais preconizados por Madalena sobrevivem e Paulo Honório é obrigado a assistir à própria derrocada. Pensando nos termos propostos por este trabalho, temos que o suicídio de Madalena representa a ruptura da execução do poder em ato. Ao tirar a própria vida, Madalena deixa o narrador em uma posição desfavorável, que descamba para um inevitável e inconfessável remorso. As últimas linhas do romance denotam o arrefecimento do discurso imperativo e autossuficiente que dava o tom no desenvolvimento da narrativa. A instabilidade do poder de Paulo Honório exige a constante atualização das posições de poder; esvaziado o objeto do ato, o exercício de dominação perde seu lastro e sua eficácia.

A violência aniquiladora do direito, descrita por Benjamin, é encenada aqui por Madalena. Após o ato do suicídio, não há mais espaço para a instauração de um novo estado de direito e isso fica claro no descaso do narrador diante do futuro da propriedade. Cogita que talvez lhe avancem os limites, mas prefere não contrariar os possíveis inimigos. O destino do filho, por exemplo, lhe é indiferente: “- Diabo leve os projetos." (p. 206). Fica claro o descompromisso de Paulo Honório junto aos seus negócios e à situação política: “- Vamos ser justos, Gondim, intervinha eu conciliador e murcho. Essa coisa estava na massa do sangue do povo. Não valia a pena brigar.” (p. 206). Mais adiante, volta seu olhar para fatos que, antes do suicídio de Madalena, não lhe pareciam dignos de nota: "As casas dos moradores eram úmidas e frias. A família de mestre Caetano vivia num aperto que fazia dó. E o pobre do Marciano tão esbodegado, tão escavacado, tão por baixo!” (p. 208). Observações que bem podiam vir da boca de Madalena. Vemos, assim, a marca forte que a esposa lhe imprimira, e o excerto deixa evidente em que medida o ideário do outro invade aos poucos a visão do narrador sobre o mundo. Deixemos claro que, apesar do despertar de uma nova sensibilidade, ele não toma nenhuma atitude concreta no sentido de melhorar ou mudar as condições precárias em que viviam seus trabalhadores. Dá-se conta, mas exime-se de qualquer movimento, pois a própria base da ação se encontra corroída, pois para Benjamin: "[s]e a violência mítica é instauradora do direito, a violência divina é aniquiladora do direito; se a primeira estabelece fronteiras, a segunda aniquila sem limites [...].”(2011, p. 150).

E de fato, está aí a medida da distância entre as atitudes de Paulo Honório e Madalena. Ao narrador, foi necessária uma re-fundação continuada e extensiva de todas as inscrições 
de poder, e a exigência de sacrifícios acompanhava a instauração do direito. À sua mulher, bastou que aceitasse o sacrifício de forma a expiar uma culpa que não existia, mas que manteve oscilantes as inscrições sociais em um estado de poder. Seguindo Benjamin:

A lei dessas oscilações repousa no fato de que toda violência mantenedora do direito acaba, por si mesma, através da repressão das contraviolências inimigas, enfraquecendo indiretamente, no decorrer do tempo, a violência instauradora do direito, por ela representada. [...] Isso dura até o momento em que novas violências ou violências anteriormente reprimidas vencem a violência até aqui instauradora do direito, fundando assim um novo direito para um novo declínio. (2011, p. 155)

Os reveses econômicos e políticos intensificavam-se, mas nada parecia tocar Paulo Honório como a ausência de sua mulher. Enquanto Nogueira enfurecia-se com picuinhas financeiras, o narrador abstraía e divagava: “[...] os meus passos me levavam para os quartos, como se procurassem alguém.” (p. 213). É com base em trechos dessa natureza que podemos vislumbrar a desordem instaurada no poder deste personagem após a morte de sua esposa.

\section{DECLÍNIO CONTINUADO}

O último capítulo apresenta forte relevo formal, pois funciona como ponta que ata o começo da narrativa - no tempo presente - ao final. É retomado o tempo da escrita, colocado no início do romance, mas, ciente do destino das personagens, o leitor entende a conjuntura a partir de outra perspectiva. É apenas após o trágico episódio que reconhece a importância da esposa: "Nesse movimento e nesse rumor haveria muito choro e haveria muita praga. As criancinhas, nos casebres úmidos e frios, inchariam roídas pela verminose. E Madalena não estaria aqui para mandar-lhes remédio e leite. Os homens e as mulheres seriam animais tristes[grifo nosso]."(p. 217).

O mais próximo que Paulo Honório consegue chegar de uma auto-crítica é:

[...] estou certo de que a escrituração mercantil, os manuais de agricultura e pecuária, que forneceram a essência da minha instrução, não me tornaram melhor que o que eu era quando arrastava a peroba. Pelo menos naquele tempo não sonhava ser o explorador feroz em que me transformei. (p. 218)

A inscrição dos sujeitos num espaço de poder exige uma diferenciação de suas posições. Neste sentido, a posição final de Paulo Honório é ambígua: ele se mantém distante, pois o narrador conseguiu de fato colocar-se acima de sua classe. Assim, mantém-se um certo achatamento da personalidade dos subjugados a seu mando: "Bichos. As criaturas que me serviram durante anos eram bichos. Havia bichos domésticos, como o Padilha, bichos do mato, como Casimiro Lopes, e muitos bichos para o serviço do campo, bois mansos." 
(p. 217). Consciente de sua 'desfiguração' moral, entende também a sua inscrição no espaço de poder como monstruosa, torta, aleijada: "Devo ter um coração miúdo, lacunas no cérebro, nervos diferentes dos nervos dos outros homens. E um nariz enorme, uma boca enorme, dedos enormes."(p. 221). O que o aflige, acima de tudo, é a consciência de que a diferenciação imposta o isolou do convívio dos outros homens: "Estamos separados! A princípio estávamos juntos, mas esta desgraçada profissão nos distanciou."(p. 220). O declínio de Paulo Honório estende-se.

\section{CONSIDERAÇÕES FINAIS}

Vimos como a trajetória de Paulo Honório se desenhou de maneira particular por conta de seu trânsito entre diferentes esferas e posições de poder. A estratégia de ascensão impetuosa, aliada a um mau assentamento das instituições de poder, incorreu num desenlace trágico, no qual as solidariedades e os vínculos de classe são rompidos, já que o narrador se investiu de uma posição autoritária. A relação entre a instauração e a manutenção do direito, juntamente com a distribuição dos sujeitos em relação a este direito, deu a tônica a uma variedade de movimentos no romance, ricos em desdobramento. Embora o foco deste trabalho tenha sido a relação do protagonista com a esposa, acreditamos que a partir dela pudemos exemplificar as demais considerações aqui traçadas. Mas a relação dos sujeitos com um estado de poder é uma constante na história de nosso país. Nos parece, portanto, que a hipótese de uma história da literatura brasileira a partir das diferentes elaborações que a violência, enquanto instauradora de um estado de poder, recebeu ao longo do tempo, não seja de todo cega.

A violência se põe, de um lado, como traço mimético do romance, indicando sua relação indissociável com as condições históricas de sua produção. Mas, enquanto traço social que deve receber uma conformação material específica dentro do romance, a violência é um problema de formulação, principalmente no nível da linguagem; assim, os temperamentos muito distantes de um Machado de Assis, de um Graciliano Ramos ou de um Guimarães Rosa têm em comum uma história, ou uma linha de filiação, onde as posições dos sujeitos dentro de um espaço de poder são de suma importância para a configuração de determinadas escolhas formais. A fratura entre as impressões sociais e a forma romance, apontada por Schwarz como um dos problemas em Alencar, indicaria um estágio no qual a forma não dava conta de elaborar o tipo de violência que geria as instituições locais. A história de uma ficcionalização da violência não deve ser entendida como a vontade factual de recriar os espaços de poder, e sim, a partir de escolhas estéticas, avançar um espaço de crítica da violência e de pesquisa da linguagem. E insistimos na palavra história, enquanto movimento de acumulação e filiação, pois é só a partir da delimitação de processos de elaboração, dados ao longo do tempo, que nos colocamos em uma posição realmente crítica. Concluindo com Benjamin:

A crítica da violência é a filosofia de sua história. É a "filosofia" dessa história porque somente a ideia de seu ponto de partida permite uma tomada de posição 
crítica, diferenciadora e decisiva, com relação a seus momentos temporais. Um olhar dirigido apenas para as coisas mais próximas perceberá, quando muito, um movimento dialético de altos e baixos nas configurações da violência enquanto instauradora e mantenedora do direito. (2011, p. 155)

Resta, ainda, muito a ser feito, mas esperamos ter demonstrado com esta análise algumas potencialidades ainda pouco exploradas que o conceito de violência apresenta, para além do que formulamos comumente como sendo violento. Ao inserir as relações éticas na equação, esperamos ter apontado para o narrador enquanto manipulador dos feixes destas relações dentro da fabulação romanesca, na medida em que também é o orquestrador da linguagem. As proposições de uma verdadeira teoria da violência dentro do romance permanecem em aberto, mas esperamos - ainda que brevemente - ter acrescentado aqui elementos para sua construção.

\section{REFERÊNCIAS}

ENJAMIN, Walter. "Para uma crítica da violência" in Escritos sobre mito e linguagem. São Paulo: Duas Cidades/Editora 34, 2011.

BUENO, Luís. Uma história do romance de 30. São Paulo: EDUSP, 2006.

CANDIDO, Antonio. "Crítica e Sociologia", in Literatura e Sociedade. Rio de Janeiro: Ouro sobre Azul, 2010.

GINZBURG, Jaime. Crítica em Tempos de Violência. São Paulo: EDUSP, 2012.

RAMOS, Graciliano. São Bernardo. Rio de Janeiro: Ed. Record, 2011.

SCHWARZ, Roberto. "Acumulação literária e nação periférica" in Um mestre na periferia do capitalismo. São Paulo: Duas Cidades/Ed. 34, 2000. 